\title{
The anomalous low and high temperatures of 2012 over Greece - an explanation from a meteorological and climatological perspective
}

\author{
K. Tolika, P. Maheras, I. Pytharoulis, and C. Anagnostopoulou \\ Department of Meteorology and Climatology, School of Geology, Aristotle University of Thessaloniki, Greece
}

Correspondence to: K. Tolika (diatol@geo.auth.gr)

Received: 27 August 2013 - Published in Nat. Hazards Earth Syst. Sci. Discuss.: 16 September 2013

Revised: 8 January 2014 - Accepted: 27 January 2014 - Published: 4 March 2014

\begin{abstract}
Greece on the basis of the available record dating back to 1958, displaying at the same time the widest annual temperature range. During the summer and autumn months, numerous regions in the domain of study experienced record-breaking maximum and minimum temperatures. Conversely, the winter period was particularly cold and January one of the coldest months over the last $55 \mathrm{yr}$. The analysis of the cold period indicates that the synoptic conditions resemble the positive phase of the Eastern Mediterranean Pattern (EMP). The predominance of these cool conditions seems to be related primarily to an intense NNW or NNE atmospheric circulation, as a consequence of the positive EMP phase. Moreover, the reduction in the floating sea ice emerges as a key driver of the formation of a low-pressure pattern and the reinforcement of the trough south of Scandinavia, which in turn strengthened the Siberia High east of the trough. This reinforcement resulted in a blocking pattern and in favorable conditions for the EMP formation. The atmospheric circulation during the prolonged high-temperature period resembles, respectively, the negative phase of North Sea-Caspian Pattern teleconnection. The observed positive pole, in conjunction with the strong southwestern circulation, results in temperature increases and in the development of a smooth pressure field that contributes to the weakening of the Etesian winds and therefore to calm conditions over the continental areas.
\end{abstract}

\section{Introduction}

The annual global average surface temperature anomaly in 2012 was $+0.14{ }^{\circ} \mathrm{C}$ relative to the $1961-2010$ mean as registered by the Met Office Hadley Centre (UK) and the Japan Meteorological Agency (JMA), rendering it the eighth-highest global temperature anomaly since 1891. During 2012, several parts of the planet, such as western Russia, southeastern Europe, the Arabian Peninsula, eastern and central parts of the USA and Western Australia, witnessed extremely high temperatures.

For Greece, 2012 was the hottest year since 1958, surpassing even the record year of 2007 (Tolika et al., 2009) and also displaying the widest annual temperature range. The temperature rise began in March and the extreme warm conditions lasted till the end of November. In particular, during the summer and autumn months, numerous regions in the domain of study (Greece) experienced record-breaking maximum and minimum temperatures. June, July, August and October rank for many stations as the hottest months of the entire period 1958-2012, while for the remaining months warm conditions showed an abnormal duration and persistence. Conversely, the winter period, from the end of December 2011 till the end of February 2012, was particularly cold and January was registered as one of the coldest months of the last $55 \mathrm{yr}$.

Given these particularly rare temperature characteristics of 2012 in Greece, this study aims to identify the leading meteorological conditions over the Mediterranean as well as the corresponding large-scale atmospheric processes and key synoptic scale features that possibly contributed to such extreme winter cooling and summer warming.

\section{Data and methodology}

Daily maximum and minimum temperatures (Tmax and Tmin) for the period December 2011-November 2012 were utilized, deriving from 15 meteorological stations over the Greek region. Apart from Thessaloniki (available from the 
meteorological station of the Aristotle University of Thessaloniki), the rest of the data was made available by the National Climatic Data Center of NOAA. Long-term (19582011) Tmax and Tmin daily time series (Hellenic National Meteorological Service) for the selected stations have also been taken into account. Furthermore, the NCEP/NCAR reanalysis data (Kalnay et al., 1996) were employed to compute the monthly mean and the mean monthly climatological and mean anomaly fields for the period 1958-2011. The NCEP data used for the analysis comprised air temperature and geopotential heights $1000,850,500$, and $200 \mathrm{hPa}$ on a regular $2.5^{\circ} \times 2.5^{\circ}$ global grid $\left(90^{\circ} \mathrm{N}-90^{\circ} \mathrm{S}, 0-357.5^{\circ} \mathrm{E}\right)$ at 00:00, 06:00, 12:00 and 18:00 UTC. The 6-hourly sea surface temperatures (SSTs) of the NCEP/NCAR reanalysis, available on a Gaussian grid (192 $\times 94$ grid points), covering the globe $\left(888.542^{\circ} \mathrm{N}-88.542^{\circ} \mathrm{S}, 0-358.125^{\circ} \mathrm{E}\right)$, were also included in the study data set.

\section{Results: meteorological aspects - links with the atmospheric circulation}

The investigation of the leading synoptic conditions and their anomalies at the level of $1000,850,500$, and $200 \mathrm{hPa}$ from December 2011 to November 2012 showed that the meteorological causes of the prevailing low Tmax and Tmin (December 2011-March 2012) and the high Tmax and Tmin (April-November 2012) are quite clear and straightforward in some cases, while in others the key drivers of such cooling or warming are more complicated, as they could originate from a synergy of several different atmospheric processes.

\subsection{The atmospheric circulation during the cold period of the year 2012}

In general, regarding the cold period of December 2011March 2012, the analysis of the synoptic conditions and their anomaly maps for several geopotential levels resemble the positive phase of the Eastern Mediterranean Pattern (EMP) as determined by Hatzaki et al. $(2007,2009)$. They showed that the EMP exhibits a pronounced inter-monthly variation in its location, structure and strength. In winter, the EMP is defined as follows: $\mathrm{EMP}=\operatorname{gpm}\left(25^{\circ} \mathrm{W}, 52.5^{\circ} \mathrm{N}\right)-\operatorname{gpm}\left(22.5^{\circ} \mathrm{E}\right.$, $32.5^{\circ} \mathrm{E}$ ), but during the other seasons the northern pole is shifted eastwards over Great Britain or central Europe. In January the northern and southern poles are located at almost the same positions, while in February the southern negative pole has shifted to the southwest. During March, the locations of the poles are completely different. The positive one is detected over the British Isles, whereas the negative one is found to the east, north of the Caspian Sea.

More specifically, January and February are registered as the coldest months in the study period. Their main thermal characteristic was the extended duration of cool conditions in the majority of the stations over the Greek region (Tjan-

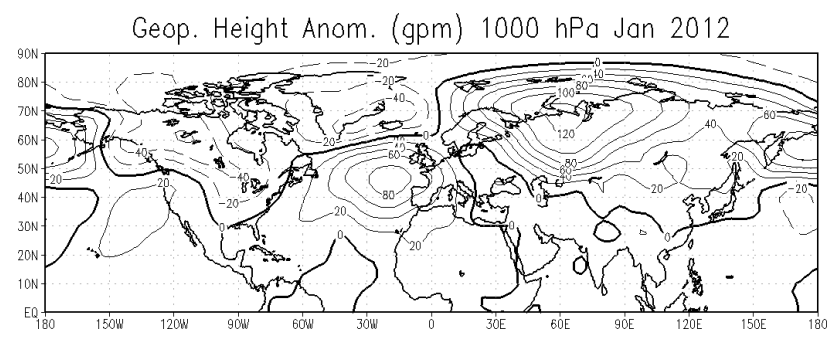

Geop. Height Anom. (gpm) $500 \mathrm{hPa}$ Jan 2012

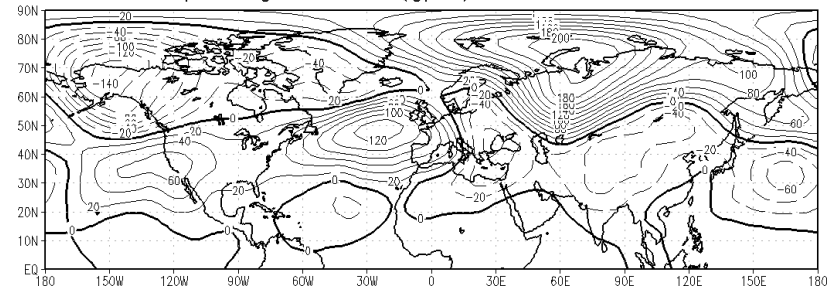

Fig. 1. Mean anomaly field for January 2012, (with respect to the long-term 1958-2011 January mean field) for $1000 \mathrm{hPa}$ and $500 \mathrm{hPa}$ levels.

uary $2012<$ Tmean $-2 \sigma$ ) rather than the extreme absolute low temperatures (Tmax and Tmin).

The atmospheric circulation during those two months is mainly anticyclonic. At the $1000 \mathrm{hPa}$ geopotential level (Fig. 1), positive anomalies are observed over the Atlantic and eastern Europe and mainly in NW Siberia where the anomalies reach a value of $120 \mathrm{gpm}$. A NW-SE oriented zone is detected between these two positive anomaly poles, extending from the eastern Mediterranean through Greece up to the Scandinavian Peninsula. Another low geopotential anomaly zone covers the whole of North America and Greenland. On the other hand, positive anomalies are found in the west of North America, over the northern Pacific Ocean, centered over the Bering Sea (January), while throughout February (Fig. 2) this positive anomaly zone is replaced by a negative anomaly one (the positive anomalies are abridged to the south).

Regarding the $500 \mathrm{hPa}$ level, the two aforementioned positive anomaly poles (one over the North Atlantic and one over NW Siberia) are observed in the same locations, but more reinforced over January 2012. A negative anomaly zone between these two poles covers Greece once again and the negative anomaly zone of North America and Greenland is extended to the west (Pacific Ocean) in comparison with the equivalent one of $1000 \mathrm{hPa}$. During February, the North America negative anomaly zone is replaced by positive anomalies, while the negative anomalies in Greenland remain, although much weaker.

The atmospheric circulation at the two examined levels $(1000 \mathrm{hPa}$ and $500 \mathrm{hPa})$ implies reinforcement of the North Atlantic High on one hand and, on the other, even greater strengthening of the Siberian Anticyclone, especially over NW Siberia. Such resurgence, noted as the greatest since 

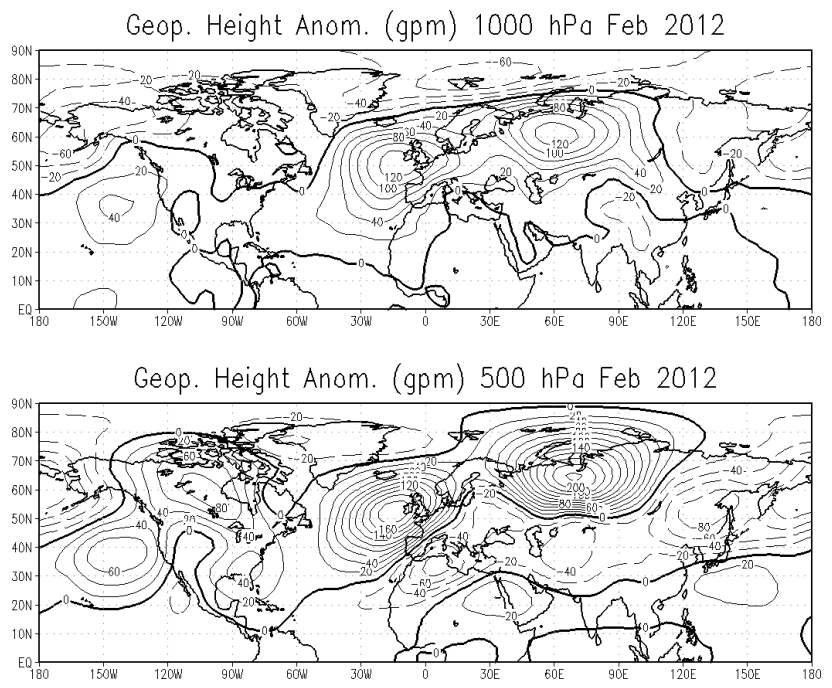

Fig. 2. As Fig. 1 but for February 2012.

1979/1980 (TCCNews, 2012), redounds to a further reinforcement of the winter monsoon in northeast Asia and a blocking in the atmospheric circulation on its western side, in the Scandinavian region as well as in eastern Europe and the eastern Mediterranean. Thus, the low temperatures with extended duration during the winter of 2012 and mainly during the January-February period could be attributed primarily to the aforementioned blocking caused by the extension of the Siberian High itself over the Balkan Peninsula and northwestern Europe. This blocking situation favored the transfer of cold air masses from Scandinavia and more probably from the North Pole to the south over the Balkans and the eastern Mediterranean. Moreover, the detection of negative temperature anomalies at several atmospheric levels $(1000 \mathrm{hPa}$, $850 \mathrm{hPa}, 500 \mathrm{hPa}$ ) in Scandinavia, the Balkans, and over eastern Europe and the Mediterranean (not shown) is in agreement with the previous statement.

Yet another question is raised. Is the reinforcement of the Siberian Anticyclone to the northwest and at all atmospheric levels a common phenomenon? It should be highlighted at this point that its extension to the west and southwest (central Europe, the Balkan Peninsula and the eastern Mediterranean) is accompanied by a cyclonic circulation at the $500 \mathrm{hPa}$ level. In other words, a positive vorticity advection (Makrogiannis etal, 1981) is found there. In the case of the winter of 2012, positive vorticity advection over to southeastern Europe is observed at the $500 \mathrm{hPa}$ level; however, at the surface the pressure is relatively low or with a slack pressure gradient. In addition, the common mean location of the center of the Siberian Anticyclone is found at $50^{\circ} \mathrm{N}$ and $100^{\circ} \mathrm{E}$ (Sahsamanoglou et al., 1991), which in our case is found in almost the same location. However, the intense positive anomaly center is detected much further to the north and west $\left(70^{\circ} \mathrm{N}, 62^{\circ} \mathrm{E}\right)$.
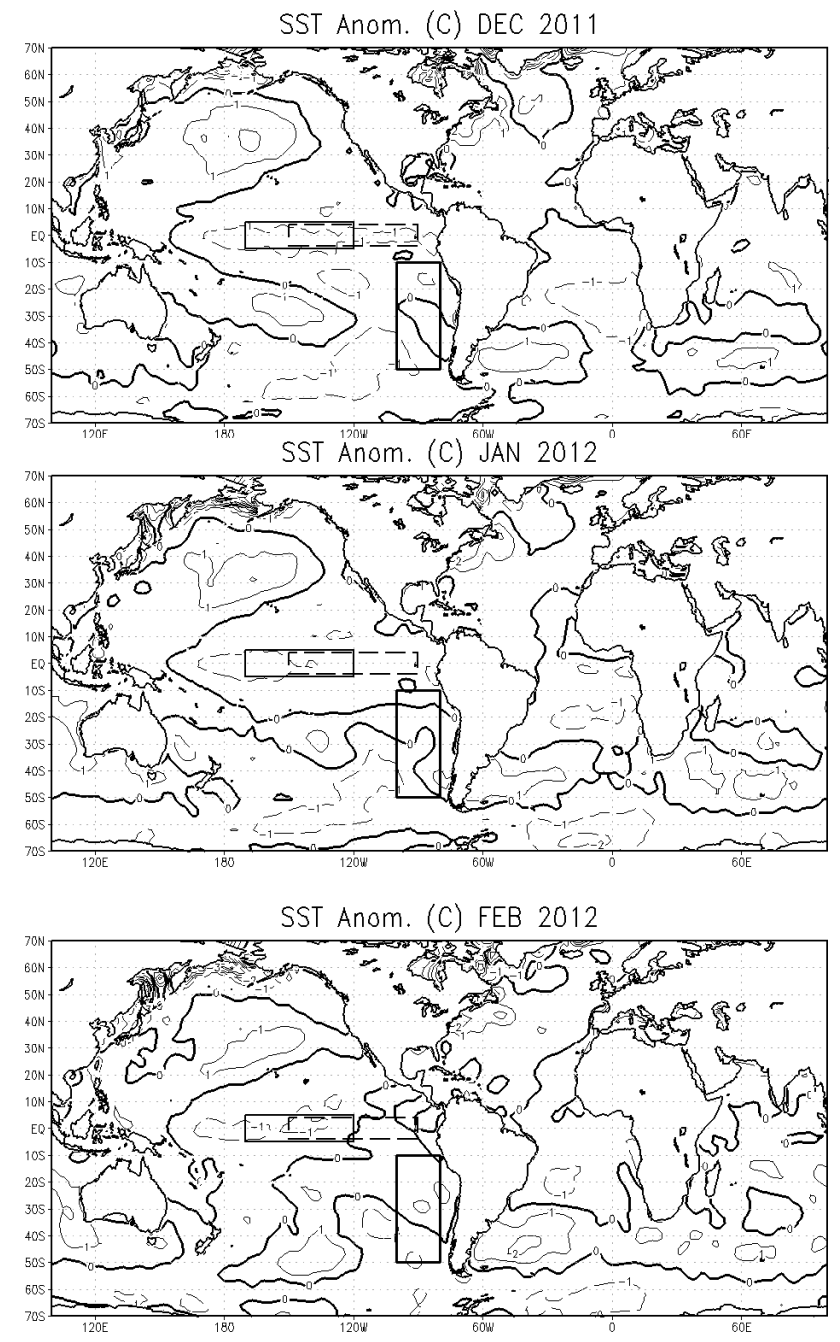

Fig. 3. Monthly mean SST anomalies $\left({ }^{\circ} \mathrm{C}\right)$ for Dec 2011, Jan 2012 and Feb 2012 relative to their equivalent long-term mean of 1958-2011 (negative values are indicated by dashed contours). The three boxes depicted are in (a). Niño 3 (long dashed frame): $4^{\circ} \mathrm{S}-$ $4^{\circ} \mathrm{N}, 150^{\circ} \mathrm{W}-90^{\circ} \mathrm{W}$, Niño 3.4 (solid frame): $5^{\circ} \mathrm{S}-5^{\circ} \mathrm{N}, 170^{\circ} \mathrm{W}-$ $120^{\circ} \mathrm{W}$, SE Pacific (bold solid frame): $50^{\circ} \mathrm{S}-10^{\circ} \mathrm{S}, 100^{\circ} \mathrm{W}-80^{\circ} \mathrm{W}$.

Furthermore, taking into account the intense strengthening of the Siberian High to the northwest and its different altitudinal characteristics, in comparison to this common structure and the blocking conditions that it caused in eastern $\mathrm{Eu}-$ rope, the Balkans and the eastern Mediterranean, it can be concluded that these are "very abnormal" atmospheric circulation conditions for the entire European region. What remains to investigate is the general atmospheric circulation on a hemispheric or planetary scale that forced these atmospheric circulation conditions and contributed to their great persistence for almost the whole winter period of 2012.

Figure 3 demonstrates that during the examined winter period, the SSTs in the equatorial Pacific were below normal mainly in the central part (Niño 3 and Niño 3.4), while 

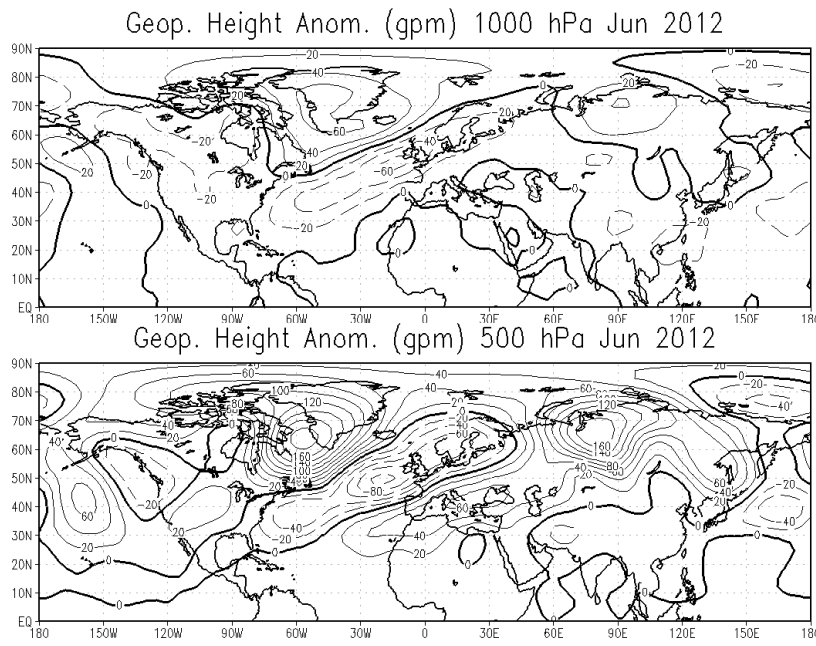

Fig. 4. As Fig. 1 but for June 2012.

slightly above normal values were observed in the western and eastern parts. These oceanic characteristics indicate the persistence of relatively slighter ENSO-La Niña conditions. Thus, La Niña-like conditions could be associated with a dipole SST anomaly pattern, with positive values in the north and negative ones in the south (TCCNews, 2012), observed in the tropical and subtropical Atlantic (Fig. 3). In addition, it can be noted that the SST anomalies found northwards and southwards of the Atlantic tropics as well as the La Niñalike conditions may contribute to the anomalous atmospheric circulation over the North Atlantic and thus possibly constitute a key driver of the eastwards shift of wave trains. Finally, the observed reduction in the amount of floating sea ice in the Arctic and especially in the Barents Sea and the Kara Sea (Honda et al., 2009; Inone et al., 2012) could have also played a major role in the atmospheric circulation conditions and the strengthening of the Siberian High at increased height.

\subsection{Characteristics of the atmospheric circulation during the warm period of 2012 (April-November)}

In sharp contrast to the winter period, exceptional warming conditions occurred in Greece from the end of March till the end of November 2012. Particularly high maximum and minimum temperatures were observed during summer and autumn (Table 1). Record-breaking temperatures were registered in June, July, August and October at the majority of the stations under study, rendering the months the warmest ones of the long-term period 1958-2012.

Due to space limitations we could not present the atmospheric circulation maps for all those months. Thus, we decided to show the most representative cases, comprising June and October, even though all the months of the warm and transitional period are analyzed.

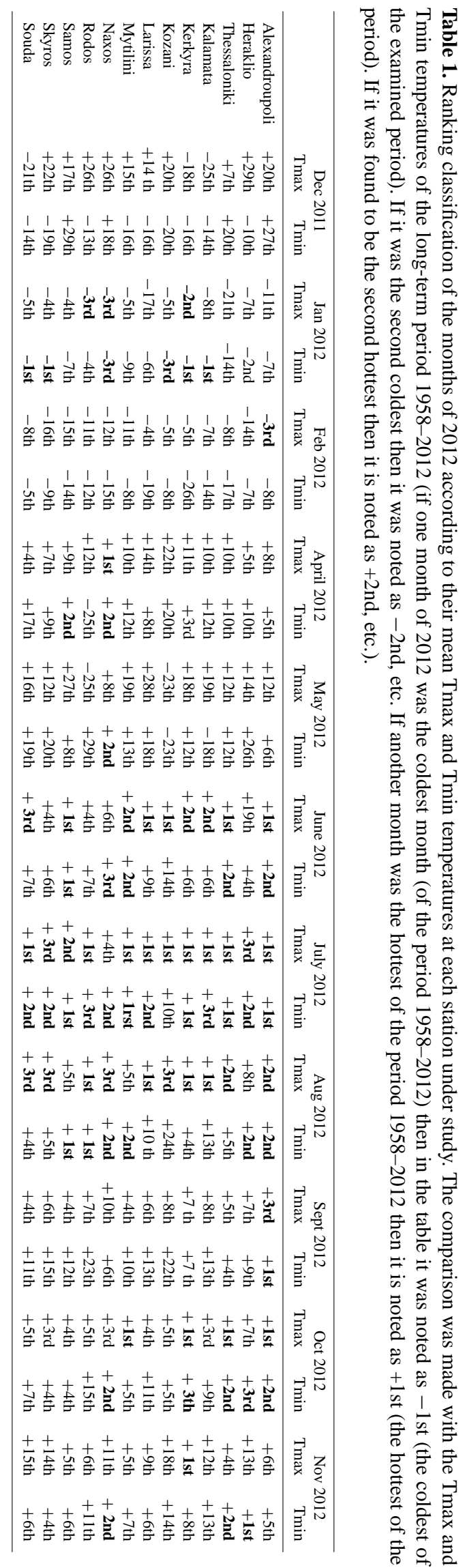

www.nat-hazards-earth-syst-sci.net/14/501/2014/ 
In the case of June, at the $1000 \mathrm{hPa}$ level, a negative anomaly zone centered over the British Isles extends from the southwest to the northeast (from the Gulf of Mexico to the Scandinavian Peninsula and northern Russia). To the east of this zone, a slack field of almost zero anomalies covers the rest of Europe, while to its northwest, an extended positive anomaly zone is found over Greenland up to the North Pole. Also, negative anomalies characterize the whole of northern America (Fig. 4). For the previous two-month period (AprilMay, not shown), it seems that the atmospheric circulation did not differ significantly from that of June, apart from the actual magnitude of the negative and positive anomalies. The same was noted for July and August, except that in July the negative anomaly field weakened both in strength and extent, while the positive anomaly field covered a large part of eastern Europe and western Siberia.

The analysis of the $500 \mathrm{hPa}$ field is in agreement with the synoptic analysis of the previous paragraph. A strong doublecenter negative anomaly zone (the first in the northwest of the British Isles and the second in the northeast of the same region) extends from the Gulf of Mexico to the north of Scandinavia in June 2012. In the southeast of this zone, another positive anomaly zone spreads out from the southwest (Sahara) to the northeast (Black Sea), with its center over the Balkan Peninsula and Greece. To the northeast, a positive anomaly zone covers almost the whole of the Siberian region. Positive anomalies are also found over Greenland, covering a large part of North America. As mentioned before, the atmospheric circulation of the previous period of April and May does not present many differences apart from the intensity and the location of the positive and negative anomalies. The $500 \mathrm{hPa}$ pattern of July and August is also similar. More specifically, for July the negative anomaly zone centered over the British Isles is further extended to the north and northeast, covering the whole of northern Siberia and parts of the Arctic region. Finally, in August, two negative anomaly poles are detected. The first and most intense one is found in the southwest of the British Isles and the second one, which is more extended, is observed over northern Siberia.

Over the next trimester (September, October and November) it should be highlighted that October is the month with the strongest positive temperature Tmax and Tmin anomalies for all stations under study. The examination of the atmospheric circulation at the $1000 \mathrm{hPa}$ level for October showed an extended but weak negative anomaly zone, with a center in the southwest of Britain covering the region from the Gulf of Mexico to northern Scandinavia (Fig. 5). Two positive anomaly poles are formed in the west and east of this zone. The first one is over Greenland and the second over northern Siberia, extending to the east. Moreover, positive anomalies characterize North America (north to the $50^{\circ} \mathrm{N}$ parallel), while to the south negative anomalies are observed. It is worth noting that during the previous month (September 2012), the atmospheric circulation was very different in comparison to the October one. A positive anomaly zone ori-
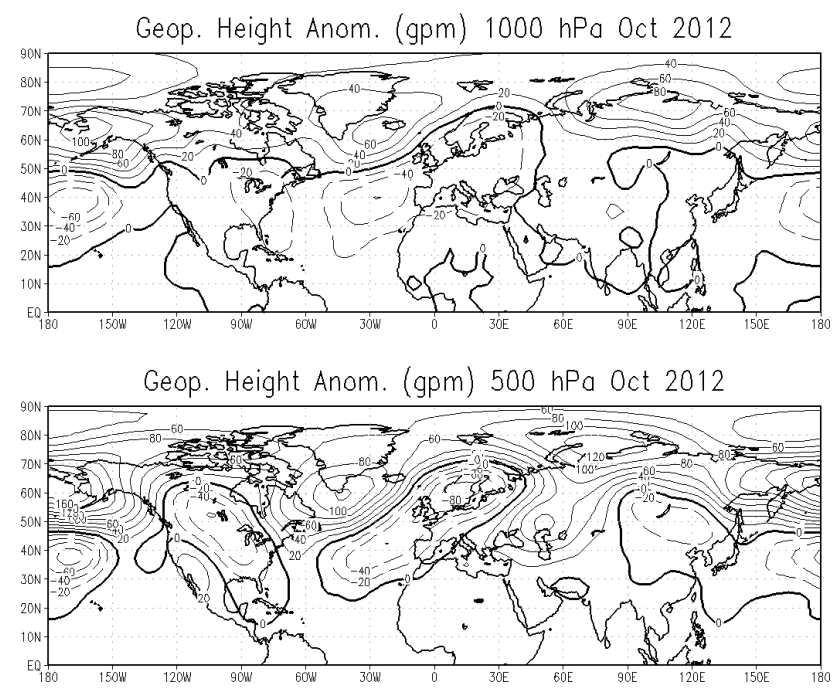

Fig. 5. As Fig. 1 but for October 2012.

ented from the west to the east covers the largest part of the North Atlantic at the mid latitudes, while to the north, another negative anomaly zone extends from North America to central Siberia. Regarding November, the atmospheric conditions also differ. A positive anomaly pole is discerned in the middle of the North Atlantic at the mid latitudes between North America and western Europe; a negative anomaly pole between Iceland and Scandinavia and another negative anomaly pole is detected in the Pacific Ocean south of Alaska.

For the same time period of September-November 2012, the atmospheric circulation at $500 \mathrm{hPa}$ creates almost consecutive (both in time and space) positive and negative anomalies, with some variations concerning the location and the intensity of the anomalies. For October, two significant anomaly poles form over the domain of study (Fig. 5). The first with negative anomalies covers the Baltic and extends from the southwest to the northeast, and the second one with positive anomalies is located over the Caspian Sea. This pattern resembles greatly the negative phase of the North SeaCaspian Pattern (NCP) teleconnection (Brunetti and Kutiel, 2011), which is responsible for the strong southwest current over the eastern Mediterranean and the Balkans, resulting in intense positive temperature anomalies (Kutiel et al., 2002). In September, the atmospheric conditions differ compared to October due to the fact that the negative pole is shifted to the northwest and extends from west to east, covering parts of Greenland. On the other hand the positive pole is shifted to the west over the Black Sea, maintaining the southwest current over the Balkans and Greece. Concerning November, the position of the two poles is also different. The negative pole is located over Great Britain and the anomaly zone extends from south to north (from Algeria to Iceland and further north), while the positive pole is found over the Black Sea, 
covering almost the whole of Europe and the Mediterranean. In each case, the south-southwestern current over Greece and the Balkans is maintained, resulting in positive temperature anomalies.

Furthermore, for the warm period from April to November 2012, the analysis of the SSTs (sea surface temperatures) in the equatorial Pacific showed that they ranged from neutral (April, June and September-November) to above normal (July-August). To the north, in the subtropics of the North Pacific, from June till October, a negative anomaly zone is formed west of North America. Further north, at mid latitudes, from August till October an extended positive anomaly zone is observed that reaches even eastern Siberia. In the North Atlantic region, at mid and high latitudes $\left(30^{\circ} \mathrm{N}-\right.$ $50^{\circ} \mathrm{N}$ ), another positive anomaly zone can be detected for the time period from May to November.

Finally, a factor that probably plays an important role in the spatial pressure distribution in the Northern Hemisphere and especially at the mid and high latitudes is the Arctic ice coverage. According to the TCCNews (2012), until the beginning of March 2012, an intense decrease in the ice coverage was detected until the mid of August, when a minimum dating back to 1979 is observed. It is worth mentioning that in 2007, when Greece once again experienced recordbreaking high temperatures (Tolika et al., 2007) over the summer period (June-August), the Arctic ice coverage also presented a minimum. Thus, it seems that there is a strong connection between the Arctic ice extent and the atmospheric circulation at the mid and high latitudes and the time and spatial distribution of temperatures in the Greek area. The trigger mechanism that causes such an effect should be examined further.

\section{Conclusions and discussion}

During 2012 (December 2011-November 2012), extreme temperatures were recorded in Greece, ranking it as the hottest period over the last $50 \mathrm{yr}$. Despite these extreme hot conditions, the time distribution of observed temperatures was not uniform throughout the year. Two different periods were detected. The first one, extending from December 2011 till March 2012, displayed low temperatures, especially for January and February (the coldest one of the last $50 \mathrm{yr}$ ). The prevalence of low temperature conditions (both Tmax and Tmin) over the Greek region during the winter of 2012 seems to be mainly associated with the occurrence of an intense NNW or NNE atmospheric circulation over the country, mainly in the mid to upper troposphere, due to the positive EMP phase. The second one, April-November 2012, was characterized by high temperatures, in particular for the June-August trimester (the warmest period for many stations of the last $50 \mathrm{yr}$ ).

In the next step of the analysis we tried to identify the main factors that contributed to the development of the EMP tele- connection and consequently to the very low winter temperatures in the area of interest. Previous studies (Hoarling et al., 1997; De Weaver and Nigam 2002; Hurrell et al., 2003; Bulic, 2010) have shown that negative or positive SST anomalies in the tropics (Niño 3 or Niño 3.4) stimulate a "wave train" that propagates eastwards and could affect the meteorological conditions over the North Atlantic in the region of the north pole of the EMP. The previous analysis provided evidence for the role of several other geographical or dynamical factors in alerting the circulation pattern in the area of interest. Thus, La Niña-like conditions associated with the SST negative anomaly observed in the Pacific tropics and positive SST anomalies in the North Pacific and the North Atlantic may be responsible for the enhanced convective activity over these regions and therefore responsible for wave trains along the polar-front jet stream in the Atlantic. Moreover, the complex relief (orography) of Greenland and Scandinavia in addition to the reduction in the amount of floating sea ice in the Arctic and especially in the Barents and Kara seas play an important role in the location and the range of the circulation patterns. The effect of this reduction in the floating sea ice seems to be the key driver of the low-pressure pattern formation and the reinforcement of the trough to the south of Scandinavia, resulting in an even greater strengthening of the Siberia High to the east of the trough. This reinforcement led to the blocking pattern that was described in the previous paragraphs and resulted in the favorable conditions for the formation of the EMP teleconnection.

Concerning the prolonged high temperature period in Greece (April-November 2012), the analysis of the synoptic conditions and their anomaly patterns showed that for April, September, October and November the spatial distribution of the atmospheric circulation resembles the negative phase of the North Sea-Caspian Pattern (NCP) teleconnection, with only some differentiations mainly at its south pole. Conversely, for the time period from May until August, the prevailing situation resembles the negative phase of the Eastern Mediterranean Pattern (EMP) more. For both cases and at all the geopotential levels, a southwesterly flow (transfer of air masses from the Sahara) is apparent over the Balkan Peninsula and the Greek region, mainly responsible for the high temperatures in our country (Maheras, 1982). As in the case of the low winter temperatures, the prevalence of the two teleconnections (NCP and EMP) is probably due to several different factors (meteorological and geographical), the temporal cascade of which is very difficult to investigate compared to the cold period one (Hatzaki et al. (2007, 2009), Brunetti and Kutiel, 2011). In previous research it was pointed out that temperatures in the equatorial Pacific ranged from neutral (April, June and SeptemberNovember) to above normal (July-August). Apparently temperatures in the Pacific and particularly in the Atlantic play a major role in the subtropical and high-latitude areas. Thus, the notably high temperature anomalies formed in the North Atlantic combined with the high temperatures of the Arctic 
north of Siberia as well as the continuous decrease in the Arctic ice seem to be responsible for the negative geopotential anomalies at all the atmospheric levels over the northeast Atlantic. This atmospheric pattern contributes to the reinforcement of the length and width of the meanders of the polar jet. It is also possible that the strong convection observed for the same time period in the Pakistan area and in the monsoon area of India, amplifying the thermal low in the regions east of the Mediterranean (Maheras, 1982), could play an important role in the intensity and location of the jet meanders. The positive geopotential anomaly pole observed over Greece, mainly during summer, with the strong southwesterly flow results not only in the temperature increase but also in the development of a slack pressure field over our country that contributes to the weakening of the Etesian winds and therefore to calm conditions over the continental areas, increasing the unbearable warm sense. Finally, it should be mentioned that other dynamical and geographic factors may have played an important role in these abnormally high temperatures for the time period of April-November, but due to lack of data it was not possible to have them analyzed at this point.

Acknowledgements. This study is funded by the Research Committee of the Aristotle University of Thessaloniki.

Edited by: P. Nastos

Reviewed by: H. Kutiel and one anonymous referee

\section{References}

Brunetti, M. and Kutiel H.: The relevance of the North-Sea Caspian Pattern (NCP) in explaining temperature variability in Europe and the Mediterranean, Nat. Hazards Earth Syst. Sci., 11, 28812888, doi:10.5194/nhess-11-2881-2011, 2011.

Bulic, H. I.: The sensitivity of climate response to the wintertime Niño3.4 sea surface temperature anomalies of 1855-2002, Int. J. Climatol., Published on line, doi:10.1002/joc.2255, 2010.

DeWeaver, E. and Nigam, S.: Linearity in ENSO's Atmospheric Response, J. Climate, 15, 2446-2461, 2002.

Hatzaki, M., Flocas, H. A., Asimakopoulos, D. N., and Maheras, P.: The eastern Mediterranean teleconnection pattern: identification and definition, Int. J. Climatol., 27, 727-737, 2007.

Hatzaki, M., Flocas, H. A., Giannakopoulos, C., and Maheras, P.: The impact of eastern Mediterranean teleconnection pattern on the Mediterranean climate, J. Climate, 22, 977-992, 2009.
Hoerling, M. P., Kumar, A., and Zhong, M.: El Niño, La Niña and the Nonlinearity of their Teleconnections, J. Climate, 10, 17691786, 1997.

Honda, M., Inoue, J., and Yamane, S.: Influence of low Arctic seaice minima on anomalously cold Eurasian winters, Geophys. Res. Lett., 36, L08707, doi:10.1029/2008GL037079, 2009.

Hurrell, J., Kushnir, Y., Ottersen, G., and Visbeck, M.: An overview of the North Atlantic Oscillation, Climatic Significance and Environmental Impact, American Geophysical Union, Geophys. Monogr. Ser., 134, 279 pp., 2003.

Inoue, J., Masatake, E. H., and Koutarou, T.: The Role of Barents Sea Ice in the Wintertime Cyclone Track and Emergence of a Warm-Arctic Cold-Siberian Anomaly, J. Climate, 25, 25612568, 2012.

Kalnay, E., Kanamitsu, M., Kistler, R., Collins, W., Deaven, D., Gandin, L., Iredell, M., Saha, S., White, G., Woollen, J., Zhu, Y., Leetmaa, A., Reynolds, R., Chelliah, M., Ebisuzaki, W., Higgins, W., Janowiak, J., Mo, K. C., Ropelewski, C., Wang J., Jenne, R., and Joseph, D.: The NCEP/NCAR 40-Year Reanalysis Project. Bull. Amer. Meteor. Soc., 77, 437-471. doi:10.1175/15200477(1996)077<0437:TNYRP>2.0.CO;2, 1996.

Kutiel, H., Maheras, P., Turkes, M., and Paz, S.: North Sea Caspian Pattern $(N C P)$ - an upper level atmospheric teleconnection affecting the eastern Mediterranean - implications on the regional climate, Theoretical Appl. Climatol., 72, 173-192, 2002.

Maheras, P.: Climatologie de la Egée et de ses marges continentales Essai de Climatologie deseriptive et de Climatologie dynamique. Thèse doctorat d'Etat, Université de Dijon, p. 783, 1982.

Makrogiannis, T. J., Bloutsos, A. A., and Giles, B. D.: Zonal index and circulation change in the North. Atlantic area, J. Climatology, 2, 159-169, 1982.

Sahsamanoglou, H. S., Makrogiannis, T. J., and Kallimopoulos, P. P.: Some aspects of the basic characteristics of the Siberian anticyclone, Int. J. Climatol., 11, 827-839, 1991.

TCCNews, Tokyo Climate Center, no 28 and 30. 2012

Tolika, K., Maheras, P., and Tegoulias, I.: Extreme temperatures in Greece during 2007: Could this be a "return to the future"?, Geophys. Res. Lett., 36, L10813, doi:10.1029/2009GL038538, 2009.

Tolika, K., Pytharoulis, I., and Maheras, P.: The anomalous high temperatures of November 2010 over Greece: meteorological and climatological aspects, Nat. Hazards Earth Syst. Sci., 11, 2705-2714, doi:10.5194/nhess-11-2705-2011, 2011. 